\title{
A Phan on Phish: Live Improvised Music in Five Performative Commitments
}

\author{
Jnan A. Blau
}

\begin{abstract}
Explored as a series of five interrelated performative commitments, the author takes seriously the notion that live musical performance, especially when it is pervaded by an improvisational ethos, can be quite powerful and well worth close examination. In particular, the band Phish, with its devout subcultural following of "phans," is mined as a rich site for critical, theoretical, and descriptive fodder. The author writes as both a phan and a scholar, drawing from his own experiences seeing Phish live on many occasions as well as from an interdisciplinary body of scholarly literature. The essay provides insight not only into the Phish phenomenon but also into the intersections of performance, communication, popular music, and critical cultural studies.
\end{abstract}

Here we go. Phish, in downtown Cincinnati, Winter '03.' They open the set with two shorter, more straightahead rockers, a solid way to get us psyched. But, it's time to get more ambitious. It's time for a big jam. "OK, what do you have for us now, boys?," I think to myself.

They start building a cloud of amorphous sound. They stretch it out and build it, looping guitar twinkles and bass whooshes around a swirl of cymbals and spacey keys. This set is about to turn a cornerI just know it. I whir in anticipation. Mike kicks in the familiar bass intro to "Down with Disease," and the crowd erupts. We know this marks the start of a potentially epic journey. We know this song has been a vehicle for truly legendary jams. Here we go ...

They wend their way through the familiar, composed part of the song. Oh, yes: they're playing with palpable tightness tonight. They're jamming already. All of us in the arena follow along, dancing and singing with gleeful abandon. The early lyric, "A thousand barefoot children outside dancing on my lawn" elicits a gentle crowd roar. We're loving every bit of this. We then come upon the song's ending coda. Everyone sings along to every word as we repeat the refrain: "But when I think it's time to leave it all behind, I try to find a way to, but there's nothing I can say to make it stop." I sing it with my all. Belt it fully.

And then ... it happens. They're off...
As popular jam band Phish was beginning to sell out midsize venues across the United States in the mid-1990s, lead guitarist Trey Anastasio (as cited in Gill, 1994) once shared,

The other day I was reading The Noam Chomsky Rea$\mathrm{der}$, and there was this great quote in there- "The beginning and end of all philosophy is freedom." [....] That quote is true, because when we get onstage we want to be free to have anything happen. (p. 40)

With Phish, the latent thrill of discovery - born of spontaneous, creative emergence - is ever present and, at its best, quite powerfully moving. Indeed, the band holds at its core an abiding relationship with improvisation, an ongoing instantiation of a musical philosophy. Manifested as extensive jamming and all manner of stage antics, Phish's performance work inhabits - as it instantiates - a space of flux; a liminal space between the familiar and the new, the justplayed and the about-to-be-played. As a performance paradigm, Phish's music radiates off the stage, into the audience, 
into parking lot scenes of gathered revelers, and into the realm of everyday sociopolitics in ways that are meaningful musically as well as metamusically.

In what follows, 1 apply a performance studies sensibility to understanding and thematizing Phish and the Phish phenomenon. I do so by discussing Phish's performance work as evidencing a series of five commitments: to flexibility, to groove, to play, to risk, and to reflexivity. Like Auslander (2006b), my focus here is thus "unabashedly performer-centered," in that I take very seriously the idea that the doing of performance accomplishes more than "just" the immediate features of the performance itself (p. 2). I appreciate the fact that when a performer takes the stage, more than music (or theatre or art) is being created, is being worked with. Unfolding as it does within a cultural-historical space, performance becomes more, particularly as it is taken up by its audience. Performance, then, traffics in values, ideas, norms/normativities - in manifold meaning(s). Phish's five performative commitments start off as a musical enterprise but transcend that music - without ever leaving it behind.

Working as both a fan and a scholar, I thus tack back and forth between what is being done on the stage and what happens to that doing once the music leaves the stage and plays itself into the wider performative-communicativecultural event. Throughout, I balance the more traditional rigor of critical cultural analysis with new writing forms (e.g., DeChaine, 2002; Denzin, 2003; Goodall, 1991; Jones, 2007) drawn from the more ineffable aspects of my personal experience as one of a devout legion of "phans" who has seen Phish perform live multiple times. In writing from a phan-centric stance, it is important to note that the tone of my work will be celebratory in nature. I recognize the implications that this approach may involve, particularly because it may be - or appear to be - the case that $I$ lack the personal and/or aesthetic distance called for by more commonly accepted forms of scholarship. Although there is plenty of room for a more traditionally critical - and apparently objective - assessment of Phish and the Phish phenomenon (some, but not all, of which appears in this essay), it is simply not the case that there isn $t$ much to celebrate in Phish; much praising and "talking up" to do. Particularly from within the vantage of a phan's experiences in/of liveness and performance, there is cause for celebration. Indeed, I cherish the visceral, emotional, and hopeful experiences that, for me and countless other phans, are part and parcel of the Phish experience. I therefore strive to somehow transpose those experiences onto these pages. Following Dolan (2005), then, my work here does play up the utopian charge that seems to be contained in Phish, in particular, and in performance, in general.

And then ... it happens. They're off. We are, all of us, plunging headlong into improvisational space.
The "regular," composed part of the song is now over. This is where it can get good. And we know it. The arena is pregnant with promise. The familiarity and safety of the previously composed section is abandoned for the excitement and risk of an improvised unknown. This is precisely the stuff that aids and abets our addictions - the need we have for periodic phixes of Phish. The band has set out to sea, to navigate the uncharted waters of heretofore unknown melodies, unplayed rhythms, ungrooved grooves. They are quite literally going where no musical ensemble has gone before, where not even they have gone before - that is, until right here, right now. It is a moment fed by the thrill of knowing, of thinking to one's self, "They've never played this before and never will again." And that's just it: the primacy of the present propels us all along as we participate, together, in this moment's unfolding.

\section{A Commitment to Flexibility}

If there is one thing that I know going into a Phish show, it is that I better be ready for anything - that I have to be open to possibility itself. The band's commitment to flexibility asks this of me. As a quality, flexibility is an instantiation: of pliability, of fluidity, and of indeterminacy in and through performance. As a mode of being, flexibility is a performed orientation, an attitude wherein we (band and audience) inhabit a psychosocial space of adaptability, of openness. As a way of relating, flexibility entails cooperation, working together to unfold a performance's contours, amenable to the contextual factors that shape our experiences. All this is signified by the term and, most important, by Phish's practiced commitment to flexibility.

This flexible orientation can be traced back to the band's inception, to the very act of naming themselves "Phish." Drummer Jon Fishman (as cited in Wharton, 2004), whose surname is purported to have been the catalyst for the band's name, elaborates,

"Phish" was a fitting name because it allowed us the
freedom to define that however we wanted to. Like, if
you call yourself "Slayer," you must slay, you know?
[. . . . . We wanted to have that open-endedness
preserved.

This ambiguous, open-ended band name accommodated for the fact that the individual band members brought to the group propensities for playing a wide range of musical styles or genres. The name "Phish," with its quirky, nondescript valence, is thus a tactical, discursive move. It allows the band to be at peace with the fact that they are unwilling, even unable, to settle on just one or two sounds or styles. 
Even the "misspelling" in the band's name seems to have built into it a cultivation of ludic flexibility. ${ }^{2}$

From the outset, then, Phish were determined to keep things flexible, to shirk the constraints of label and genre within their embraced paradigm of improvisation. Genre became, simply, genre(s), a sort of democratized (though, it must be noted, also a potentially facile and/or essentializing) engagement with diverse musical styles. What was lost in depth was gained in breadth: whatever focus is sacrificed by not sticking to one genre is made up for in an appreciation forin the very performance of - musical diversity. "Phish" thus resists the modernist predilection for narrowing, typecasting labels. Rock journalist Thompson (1997), notes,

Such eclecticism [i.e., genre flexibility], of course, serve[s] a number of purposes, not only offering a showcase for each group member's own personal influences, but also defying any passing critic to simply fasten onto one prevalent sound to pigeonhole Phish. (p. 111)

What may be referred to as genre-promiscuity is precisely what prompted another journalist (Resnicoff, 1996) to say, "Like no other pop phenomenon, Phish spawns in all rivers" (p. 75). Truly, one of the defining characteristics of Phish is that seemingly all musical styles or genres are fair game, from Bluegrass to Rock to Jazz to Heavy Metal to Blues to Calypso to Classical to Prog Rock. Phish's relation to genre, it could be said, functions as a way to maximize possibility, to encourage experimentation, to foment discovery.

Phish's genre b(1)ending thus evidences a thoroughly postmodern orientation, one in which a loss or lack of genre stability and/or recognizability can be likened to the missing power and diminished presence of what Lyotard (1984) terms metanarrative, a condition that is in part characterized by an ineluctable "heterogeneity of elements" (p. xxiv). Phish's performance work is not, under these conditions, "governed by preestablished rules" (Lyotard, 1984, p. 81). Indeed, the band and their performance work cannot be "judged according to a determining judgment, by applying familiar categories to the text or to the work" (Lyotard, 1984, p. 81). This flexibility is thus a throwing off of rules, positing possibility itself as the desirable "rule" for musical performance. Truly, textual freedom - an ability to "write" not just differentyet-somehow-related music(s) but, also, experiences, stories in the wider phenomenon - seems the only hard and fast rule with Phish.

Along with genre $b(1)$ ending, Phish's composing also bears the imprint of flexibility, with the band often working out a song's formal features in and through live performance. "The Moma Dance," for example, started out as an instrumental named "Black-Eyed Katy" and only later picked up lyrics and appeared on the studio release The Story of the Ghost. Another track from that album, "Ghost," started off as fast-paced, terse funk before settling, over a period of about a year, into its much spacier, mellower, and hypnotic groove, one more befitting of the song's title and subject matter. As performers who embrace the flexibility inherent in an improvisational context, Phish work and re-work their material on-the-spot. ${ }^{3}$

Flexibility, then, is part and parcel of the Phish experience and is why no two Phish shows are ever alike. What songs are played, and when and for how long, is an open, ever-changing matter. Maybe they'll play "Camel Walk," a rarity performed only as a very special treat. Or, they might offer up a cover: perhaps a stretched-out meditation on the groove at the heart of Robert Palmer's mid-1970s obscurity "Sneaking Sally Through the Alley." At least as exciting as song selection and song placement, however, is the element of song jamming. In this respect, absolutely anything is possible. The regular four or so minutes of the studio recording of "Ghost," for example, can morph into half-hour explorations, contorting and canoodling around a hypnotic, slinky bass line and driving drum beat, first ebbing and then flowing in a dynamic display of musical meandering. Songs like "Ghost" have been known to simply take off and never return, journeying far and wide, alighting some time and some where else - in a different key, a different time signature, and thus in a different psychoaffective space - altogether.

As they jam, Phish stretch the very limits of musical intelligibility, accessibility, and coherence. Bassist Mike Gordon (as cited in Thompson, 1997) has explained that jamming provides opportunities "to try to stretch certain limits and do it in a thoughtful way. So, for the listener, it's a matter of opening [one's] mind, to be able to accept that as being something desirable" (p. 25). Sometimes Phish's improvisational forays hew more or less close to home, sticking with the time signature and the chord progression of the starting-point song. These are known in phan vernacular as Type I jams. ${ }^{4}$ At other times, the song that launches a jam is left far behind, the band passing through varied melodic and rhythmic territory: Type II jams, wherein new time signatures and new chord progressions are written on the spot.

In a very real sense, such jamming tests the already flexible limits of improvisation itself - and thus tests the band's and the phans' very commitment to flexibility. These kinds of jams are interesting and important precisely because they shirk the desire for fixity in meaning and the need for predictable experiences. Through improvisation, the text(uality) of each distinct Phish song can always, potentially, be tinkered with, stretched out, re-written, re-cast; altered, honed, (re)interpreted. A good, solid setlist (the sum total of song selection, song placement, and song jamming) is thus something of an achievement. And this achievement, reflecting creative decisions enacted by the band, is performed evidence of the band's commitment to flexibility. 
There is probably no better or more iconic demonstration of Phish's commitment to flexibility, and of their intimate audience relations, than a "Big Ball Jam":

Brad Sands [Phish's road manager] throws beach balls into the audience, after which the band bases their improvisation on the movement of the balls, playing when the balls are touched and holding a frenzied note when the balls are grabbed and held by one or more audience members. (Mockingbird, 2004, p. 869)

At first blush, a "BBJ" appears to be a fun and seemingly meaningless musical game. Taken in the context of Phish's overall performance paradigm, however, it picks up deeper significance. Such an "antic" evidences their commitment to fully explore the possibilities of improvisation; asks maximum flexibility of them as musicians, because they have to, on the spot, decide what and how to play. A "BBJ" also puts the band members into a very special relationship with their audience. It is flexibility performed: literally, Phish performing what the audience plays - as the audience plays.

Phish's epistemology of open-ended flexibility seems to be predicated on a belief that exploratory improvisation is a worthwhile endeavor, that music worth playing and hearing will be manifested in and through this process. Echoing this, Gordon (as cited in Koransky, 2000) sums up Phish's distinct approach to improvisation: "What's always seemed unique about us is that rather than just having a jam or a big guitar solo, we've had the idea of improvising the form. It's sort of songwriting on the spot" (p. 26). Relatedly, Fishman (as cited in Koransky, 2000) elaborates an experience of doubled epistemology as he talks about Phish's improvisational excursions: "I would not call it knowing what's going on. But it's not necessarily not knowing what's going on. It's knowing that you're together in not knowing what's going on!" (p. 28). In not knowing when or how things will come to pass in Phish's performances, no one quite knows when or how they will become significant. Any given performance moment thus carries with it the latent potential to be experienced as - and thus to become - meaningful. Meaningfulness is, in its flexible contingency, productively indeterminate. Songs become vehicles, veritable launching pads, and their meanings, in this way, are rendered anew each time. With Phish, meaning formation is very much a flexible process. The band's work as musical performers is thus a stylized repetition of variance, of adaptability, of polyvalencedmultiplicity, of productively ambiguousmeaningfulness: their commitment to flexibility is, therefore, quite thoroughly performative.

The primacy of the present propels us all along as we participate in this moment's unfolding.
Fishman and Mike, on drums and bass, lock into a steady, riding groove, deliciously pull us forward. Mike's bass line rolls and the jazz of Fishman's cymbal rides. Swing, swing, swing. It's a groove that could go on for days. It positively pulses. It is locked down and shows no sign of letting up, pointing dead ahead toward some great, marvelous uncertain. I am tied in and could not be any happier. My head nods in rhythm. My eyes are pursed in languid veneration. Every ounce of my dancing body is lapping it up and then throwing if off. Yes, yes, yes: it's one of those grooves. Mike's bass falls into a steady syncopation of up and down, chasing that back beat just far enough behind. Mike and his bass playing work on the level of the viscera: equal parts chunky funk and lithe smoothness. Fishman, ever elegant, plays his drums alongside Mike's bass. He provides the essential, skeletal beats: cymbal ride, bass drum taps, and snare snaps - working in between silences just so. When they work together like this, it's downright hypnotic. Propulsive. A dynamic anchor from whence to groove.

Trey plays along on his guitar with an understated yet oh-so-tasty solo. With his distinctive tone and wily axe dynamics, he can veer from over-thetop and out-of-control to achingly graceful and elegantly placed. Right now, it's not one of those rip-roaring solos to end all solos. But, I appreciate it all the more for its sense of deference to the groove itself, its willingness to work with and in the groove, not above or against it. Yes, the groove is working, working all around.

\section{A Commitment to Groove}

Phish's commitment to groove is a salient feature of their live music, and this commitment has become deeper and more meaningful as they have evolved as performers. So, given this, what is signified by the term "groove"? How do I articulate it/one/them? 'That, of course, is a tricky task.

I know my body knows a groove when it hears one. Yet this is implicit knowledge, unspecified knowledge (though no less real for that). Put another way, a groove is that "part" of music that involves rhythm and beats and pulsations. Technically speaking, grooves involve repetitions of two or more different musical ideas over a period of time; a looped (i.e., cycled) collection of seemingly small performance choices that, taken together, achieve a swinging, propulsive feeling (Zbikowski, 2004). A groove, then, involves "a small group of musicians working together, each contributing parts to the composite whole" (Lbikowski, 2004, p. 272). Grooving musicians endeavor to create "a large-scaled, multi-layered pattern that involves both pitch and rhythmic 
materials, and whose repetitions form the basis for either a portion or all of a particular tune" (Zbikowski, 2004, p. 275). Given a groove's relative constancy, it cannot be sung the way a melody can be. A groove is felt. If melody (in the form of a tune) is music's mind, the groove is its body.

Us phans enjoy a good groove even as we may not have explicit knowledge or precise insight into what one is and/ or how one works. Speaking as a phan, 1 would say that grooves pulse - with and for us. They compel somatic response, whether a simple finger or foot tapping or a fully dancing body. Quieting down and then building back up, with the groove an underlying blanket of rhythm, Phish jams can pull the audience along by dint of their dynamic of tension-and-release. Sticking to a groove allows solo jams to occur in the first place; but sticking to a groove also showcases the powerful drive of a groove in and of itself. Audiences move their bodies attuned to the groove, not as they follow the ins and outs of the solo.

Phish can stick to a groove and just "jam out": while one member solos, the other three maintain an underlying, elemental rhythmic force. Yet the type of improvising 1 most strongly associate with Phish's commitment to groove is what has been posited by phans as Type III jamming. With this kind of jamming the main focus is not on soloing. In fact, in this particular improvisational orientation soloing is either nonexistent or qualitatively different. Type III jams are accomplished when the band plays more rhythmically than melodically - when they groove, hard. It is fitting that these sorts of jams, with their sexy/sensual/visceral, deceptively simple grooves are also referred to as "Pornofunk": they are thoroughly entrancing, with bass lines that undulate hypnotically; easy, propulsive drum beats; space-y, ambient keyboard washes; and funky guitar strumming. A listen to live versions of the song "Sand," for example, typifies this kind of improvising, which has a meditative quality to it, an almost Zen-like relationship to music and rhythm characterized by patience and perseverance. There is an element of now-ness in this kind of improvising, as if nothing else matters but the groove taking place in - and giving rise to the experiential contours of - the right-here-right-now.

Grooves provide concrete evidence of the band's synergistic skills. Phish's grooves often feel as if each member is tuning in and contributing exactly what is called for by the groove itself - nothing more, nothing less. This does not mean that that reverential deference results in stasis, in no change. Rather, the ineluctable excesses of improvisational practice always mean that the groove is never wholly prefigured. Indeed, a creative double bind between flexibility and grooving is at work here: sticking to a groove, or "sharing in the groove" (as one Phish lyric puts it), provides the necessary (but not necessarily sufficient) backdrop from which to venture forth, to explore fluid change. As Anastasio (as cited in Ellis, 2000) puts it, "Night after night, you want to play because of that feeling. You get out there and start a groove, and that groove brings people together" (p. 102). Groove, then, signifies at one and the same time both stability and flux, repetition and variance, constancy and ephemerality, for both the band and its audience.

It is one thing to grant or recognize that phans know grooves that they can respond to a groove, wherein response is always already identification - but it is quite another to account for that knowledge. It is worthwhile, therefore, to dwell on the epistemological considerations of grooves, particularly given the fact that people seem to "know a good groove when they hear it" (Zbikowski, 2004, p. 272). Citing cognitive anthropology, Zbikowski (2004) understands grooves as phenomena whose creation and reception rely on "conceptual models" embedded within both individuals and the wider culture (p. 280). Grooves are wired into our individual brains, allowing us to perform them, to recognize them, to enjoy them. Yet, at the same time, they are in - they reflect, and performatively enact - the collective, cultural creation and reception of music. Performances of grooves, then, involve a musical text comprised of cycled regular, yet differentiated, rhythmic elements that, because they draw and act on previously held individual and collective schema for understanding music, have a contextual, interactive force to them. Given this, Phish's commitment to groove matters, in that a groove's performance and identification - and its full enjoyment - are always already both individual and cultural.

Whereas Phish's commitment to flexibility welcomeseven zealously explores - change, their commitment to groove works on/from a different dynamic. Grooves hold to a steady center - or at least to a center that shifts only gradually, with deference to its immediate past. Grooves, then, are still explorations. But they are explorations that unfold as fluidly as possible. Where flexibility signifies altering course(s), grooves entail change-within-continuity.

Yes, the groove is working, working all around. Trey finishes out a phrase and then simply drops out altogether, stops playing his guitar. He lets the groove groove on on its own. I see him walk over to Mike and whisper something in his ear. He then turns to look out at the audience and makes a sweeping gesture with his open hand, across the sea of dancing, pulsing bodies. Oh, he sees something. He is cued in to the wave-like gestalt we are all now a part of. There we are, dancing our bodies and bobbing our heads. Mike looks out with him, nods in agreement. I notice them noticing. So does the rest of the audience, and they swell back in response. The recognition floors me. 
The pit of my stomach now squirms with an intense emotional wash as 1 look around the arena, taking in the tides of an audience hopelessly united under this one groove. I really think that every single one of us is dancing along to this glorious, expansive music. And the throb of the groove grooves on on its own. Drums, bass, and keys. Just doing it. Pouring it on sweet and just-right thick. Quite a moment, burned into my being.

\section{A Commitment to Play}

Whether at the level of song lyrics or on a grand scale at their summer festivals, Phish's performances evidence an abiding commitment to play. And their play(ing) is meaningful, important work. Miracle (1992) has defined play as encompassing pleasure, altered states of consciousness, control over one's actions, and an awareness of alternatives or possibility (p. 60). Play, in this light, is no mere activity; it is an experience. Play involves bodies, emotions, and ideas, all of which interact and resonate on personal as well as sociocultural levels. From Bakhtin (1984a and 1984b) and his notion of the carnivalesque to the work of 'Turner (1988) with performance and ritual, much has been written with regard to play. Indeed, performance itself has been defined as "ritualized behavior conditioned/permeated by play" (Schechner, 1998, p. 95). Play and performance, then, are in a very real sense mutually constitutive. One is never farexperientially, functionally - from the other.

Phish often has been dismissed, or at least not taken seriously, on the grounds that a certain element of "silliness" threads its way through their songwriting and their live performances. Phish's lyrics, for example, contain plenty of playful silliness. The lyrics "Simbop and Bebophone, Skyballs and Saxscrapers," from Phish's song "Simple," are the culmination of a playful lyrical buildup in which the words "simple," "be-bop," "skyscrapers," and "saxophone"- each mentioned gradually in the song's unfolding - are recombined in the song's last stanza. Phish's stage "antics" are arguably less silly and more aesthetically minded than their lyrics. 'There can be no better example of Phish's playfulness, however, than their summer festivals. These are ethnographically rich events, with both band and phans setting up camp for two or more days, several sets of music each night, fairgrounds, art exhibits, and much, much more. The festival grounds, aside from lodging tens of thousands of revelrous phans, are the site of myriad playful moments: from, to name only two examples, a "'Runaway Jim' 5K Memorial" marathon (named after a song about Jim, the kleptomaniac $\mathrm{dog}$ ) to a five-story Port-o-Let Pagoda (several portable restrooms stacked on top of each other and lit by candles).

Probably the most striking instantiation of Phish's commitment to grand-scale playfulness happened in 2003 at their I'T Festival: a performance event now known as the "Tower Jam." It has been described thusly (LivePhish.com, 2003):

The band magically appeared atop the control tower of the former Loring Air Force Base and played an improvisational set while the tower was bathed in lights and dancers on rappel lines swirled in synch with the music and lights.

The music was an unannounced, middle-of-the-night performance of experimental soundscapes, improvised ex nihilo, and combining elements of free jazz, ambient electronica, and space rock. Visually, the Tower Jam saw an airport control tower transmogrified into a multilayered performance art installation, with various lighting effects, hanging banners swaying in the breeze, and dancers dangling from the top of the tower - all in all, an effect not unlike something one might encounter if a Cirque du Soleil performance was held at a decommissioned Air Force base, with Phish providing the live soundtrack. Keyboardist Page McConnell (as cited in Wharton, 2004) shares that "it was intense, for a lot of people. [. . . . W We're actually creating music in a way, and in a place, and in an environment that [has] never really been done before." Indeed, the Tower Jam manifested many of Phish's commitments to improvisation, but none more than play. It provided ample evidence of their willingness to playfully explore new performance possibilities, with their own and their audience's generative amusement a foremost consideration.

At this point, a brief discussion of power and politics in the Phish phenomenon seems appropriate. Though to my knowledge the band has not explicitly discussed the matter, the juxtaposition between the general tone and feel of Phish's performances (most saliently in the lower Jam) and the associations with and realities of an Air Force (and of the military industrial complex in general) do seem worthy of note. I was not at IT, but have been to enough of Phish's performances to imagine that it really must have been surreal, engaging, and even mind-bending to experience the eventuation of all that the festival encompassed (particularly the lower Jam) while standing on grounds where, quite literally, wars have been launched; where rigidity and extreme discipline complete control and enforced predictability-were previously the norm. The political implications, of course, are rich.

In my observations, Phish's relation to politics - or their political work - has mostly been understated and implicit. They have not been a "political" band, with largely apolitical lyrics, and little to no explicit discourse - onstage and off - regarding political issues. This, of course, is not to say that their work does not have effects and consequences that matter politically. This is fodder for a discussion elsewhere, but the point $\mathrm{I}$ am interested in making here is that we see evident, with performance events such as IT and the Tower 
Jam, both the latent power and political potential of Phish's work. The vicissitudes of Phish's music, and of phan culture, always already unfold within a contextual matrix that includes American and Western social, economic, and political practice.

In light of this, then, Phish's play is more than "mere" amusement. If it is considered in metacommunicative terms, their playfulness can be understood as subjunctive, even subversive. The term "metacommunication," originally coined by Bateson (1955), gets at the idea that communicative messages involve not only explicit content but also implicit content that somehow sheds light on the significance of the mutually constitutive process of communication. Phish's play, whether in singing nonsensical lyrics, in having fun with band-audience interactions, or in staging full-on surrealistic performance events, is metacommunicative through and through. The band's acts of playfulness communicate beyond their surface-level content as they signal possibility and connection. Phish metacommunicate that several of the components of a Phish show (and, by extension, of performance in general) can be played with: the content, intelligibility, and/or tenor of a song's lyrics; the look and feel of aesthetic performance; the nature of performeraudience interactions; phans' very being-in-the-world.

The messages delivered in and through Phish's play are thus "often serious beneath the outward trappings of absurdity, fantasy, and ribaldry" (Turner, 1988, p. 124). At times spectacular, these playful instances function as devices to "make visible what has been hidden, even unconscious" (Turner, 1988, p. 125). Though Phish's playful exercises may appear to have no "point" to them, both band and audience know that each instance, each silly "antic," is potentially meaningful. Their playfulness possesses, in effect, a quality of "dangerous harmlessness," and is dangerous precisely because "its lightness and fleetingness protect it" (Turner, 1988, p. 169). The apparent innocence of play is thus precisely where its power resides. Truly, the importance of play lies in its ability to present

ludic critiques of presentness, of the status quo, undermining it [ . . . ] part of it subverts past legitimacies and structures; part of it is mortgaged to the future in the form of a store of possible cultural and social structures. (Turner, 1988, p. 170).

Play has the very real potential to accomplish more than its form and content may indicate. In this sense, Thompson (1997) is quite on-point in venturing that "Phish's appeal [ . . . . contain [s] a fair degree of conspiratorial glee" (p. 166). Phish, in some way and on some level, know that their play plays well - and that it plays meaningfully. Resonating with theories of performativity, play is functional: something done that results in further things done. Paraphrasing
Butler's (1990) famous edict, Phish's performance work can thus be appreciated as the playful repetition of possibilized acts.

The fact of the matter is that, as a phan, I never know what to expect from the band, musically and metamusically. I embrace and relish this fact as central to the experience of going to a Phish show. As I see it, this flies in the face of a wider sociopolitical context in which expectations - whether pertaining to mode of dress, or to orientations toward work and leisure, or to emotional openness and bodily expressivity - are that one should maintain and reflect the prevailing dominant culture, not play with or challenge it.

Truly, then, the "play impulse" (Marcuse, 1955, p. 187) is tremendously important: it is a necessary part of an ongoing quest to work out the conditions that have given, and will continue to give, shape to individual and collective experience. Following Marcuse (1955), it could be said that the myriad "inhuman existential conditions" that seem to pervade modern civilization practically call for, if not demand, such playful activity (p. 187). Indeed, the play impulse "does not aim at playing 'with' something; rather it is the play of life itself, beyond want and external compulsionthe manifestation of an existence without fear and anxiety, and thus the manifestation of freedom itself" (Marcuse, 1955, p. 187). Phish's play(full) work plays with/in contingency, fostering a psychosocial space in which differences, discrepancies, and distortions are vital to ongoing processes of resistance and change. Speaking again from my own experience, a Phish show can thus be a productive disruption, a form of liberating subversion (or is it subversive liberation?).

Quite a moment, burned into my being.

Page, stage right behind his bank of keyboards, tickles his piano for a while, swivels to his Clavinet for some funky punches, then to his Rhodes for a few choice modal chords. A subtle yet essential aural backdrop. His presence is that of a knowing Zen master, providing a foundation that can go unnoticed next to Trey's wail, but that is no less important. I take a moment to tune in to what he's putting out. A ghostly synth pall gently fills the air and then falls away. A moment later, a tickle of notes from the upper range of his grand piano. The notes dance with the groove like some sort of blink-and-you-miss-it fairy. Next, he swings 'round on his stool, fixes us with an extended wash of organ. Page works his mantra of notes, stitching it all together. His is a Kabuki play of keyed in fingers fingering keys.

Still next to Mike, Trey tries out some more jazzy chords. He seems to strain against the tones, seeing where, or how, he might push the groove. Or if he wants to. His bandmates keep it going, let him chart 
the course. The jazzy chords aren't off the mark, but I don't think they're it, either. A sense more felt than concretely understood. Then, Trey walks back over to his stage space, tweaks a few guitar pedals and, ever so gently, drops back into the jam again. A series of delicate, high-end staccato notes. It's just sublime how he does it. A leaf falling into a stream. He's got it. Steady, finger-picked riffs - he's found a way to work it out. "This is good, really good," I think to myself.

\section{A Commitment to Risk}

Moments come to pass in the course of improvised musical performance in which what is played by the musicians, and heard by the audience, is somehow imperfect, deficient, incoherent, unsophisticated, or unsuccessful. It is inevitable that the live moment will yield mistakes. It is an ontological fact of performance that human fallibility should be inescapable. In other words, improvisation is, by its very nature, risky. Several authors (e.g., Alperson, 1984; Brown, 2000; Hamilton, 2000) have written about the ways in which improvisation and risk are, necessarily, mutually entwined. As Brown (2000) puts it,

If things are going well, I wonder if [the improviser] can sustain the level. If [the improviser] takes risks that get [her or him] into trouble, I worry about how [she or he] will deal with it. If [the improviser] pulls the fat out of the fire, I applaud. My overall interest [...] is predicated on both aspects of [the improvised music] - the quality of the result and the adventurous character of the actions that generate it. (p. 121)

Risk, then, can be understood "as a condition of efficacy" in performance in general, and in improvisational performance in particular (Chvasta, 2002, p. 15). The not knowing what exactly will have been played (which defines improvisation) signifies at the same time not knowing exactly what is being played how. Indeed, setting out with no script or score, as improvisers do, is to invite, if not welcome, both sides of risk's efficacy: the potential for positive achievement (moments often described and experienced as inspired, magical) and the potential for negative achievement (moments that require patience, forbearance, perseverance).

A reckoning with risk's ontological preeminence in/as performance presents a two-pronged epistemology in which achievement is always already a matter of $\mathrm{im} /$ possibility, an $\mathrm{im} /$ perfect reconciliation of dialectical tensions. From the perspective of the performer, risk is concomitant with the knowledge that success (whatever that may be, or turn out to be) may or may not be achieved during the course of performance. So, though most improvisers spend considerable amounts of time and energy preparing for the live moment (through extensive practice and deep knowledge of music and of the musical tradition within which their work unfolds), the actual moment of improvisation always entails risk. "The improviser," as Alperson (1984) has said, is therefore "in the most precarious position of all" (p. 23). ${ }^{5}$ An improviser is situated in/by risk, poised somewhere between safety and risk, success and failure; between past and future, preparation and inspiration, context and performance. Because the music is encountered as it is being created, not afterwards (like a painting or a musical recording most often are), we could then say that improvisation is both process and product. With this, we adumbrate a special kind or mode of performance, one in which the performing and the performed become wrapped together into an interesting, complex whole, with risk (and all it signals and entails) an essential, constitutive feature.

Phish know this to be the case: not only do they know that they risk, they also meaningfully embrace risk's consequences as part of what they accomplish as performers. A memorable, well-wrought Phish jam is thus always latentand never a given. One of the main reasons us phans strive to see Phish perform multiple times is in a very real sense based on an understanding and appreciation of what is at stake: a recognition that not all jams are created equal, that sometimes they work and sometimes they don't. Though aesthetic judgment is always permeated by a degree of subjectivity, phans, like the band itself, are able to identify jams that, say, didn't come together, that went nowhere special (phan literature is full of debates about and lists of best and worst jams). We listen closely to the notes, to the musicians, to the interaction between the parts and the whole. So, again, risk cuts both ways. The band risks failingmaking mistakes, not producing something particularly engaging or interesting. But, given that sublime, very accomplished improvising can come to pass on any given night, phans risk missing it - missing out - if they're not there for the next "epic" performance moment.

I speak of risk as a commitment precisely because there is acceptance of the fact that the good must be taken with the not-so-good. In essence, the band's choice to engage improvisation on an ongoing basis performatively enacts an understanding that their performing brings with it unknowability. As a commitment, risk therefore presents a peculiar aesthetic and evaluative frame. There is a sort of safety involved, inasmuch as all of us (band and phans) are willing to enjoy the highs and the lows, to take a relatively flexible and forgiving orientation toward what is "supposed" to happen onstage. But, this is not to say that there are no evaluative criteria at work. On the contrary, precisely because we do take so seriously - are so "into" - what happens onstage, we are ever-alert, ever-listening. To be sure, both the phans and the band are more than willing to issue 
judgments about the success or failure of any given performance. Indeed, as Brown (2000) notes, "In a situation involving risk, something of value must be at stake -in this case, the formal character of the musical product" (p. 119). The fact of the matter is that we do care about successful performance - deeply. The central point is that Phish's performances, pervaded as they are by improvisation, are a special case of aesthetic achievement: risk does entail imperfection, but imperfection does not mean failure in the more traditional understanding of the word. A successful jam is thus not accomplished, in the sense that it is set out as a definite, concrete goal that has been preidentified and which will then be reached by dint of will and determination. Rather, it is strived for, in an almost Platonic sense.

As the rhythmic anchor of the band, Phish's drummer knows this all too well, and describes the process in intriguing terms:

Our music invents a geography. It draws a big map. It starts out on land, where we build the boat, which is the written and arranged part of the music, the launching pad. Once we get into the water, we're like Columbus. We don't know the next time we're going to hit land, how wide the body of water is, or even whether we're crossing a lake or an ocean. (Fishman, as cited in Gehr and Phish, 1998, p. 54)

The process, to follow the metaphor, is one of exploration, of discovering what sounds lay ahead in the unmapped territories that can only be accessed aboard the vessel of improvisation. Thus, though exploration may or may not lead to some heretofore uninhabited and unenjoyed aural paradise, the voyage itself is never in question. Truly, it is impossible for me to imagine Phish - and how I experience them as performers, the impact and power that their work can have - without the element of taking risks, constantly.

"This is good, really good," I think to myself. Each one of these four human beings is doing exactly what needs to be done right now. It just floors me, how they are able to come together like this. Loose and tight all at once. Right now, this is just sublimeness. And I'm right here, with them. I can't help but travel along, as they explore the tonal and rhythmic ins and outs of their collective improv, this groove descended from some Mothership from who knows where. I intimately follow each turned phrase, each punched chord, each snap and thump. Worldly concerns and trivialities? They ceased to exist for me somewhere ... back ...

Eyes closed completely now, body moving, mind here and there and everywhere...

In this moment, it becomes clear to me - crystal clear-just how meaningful a good jam is. It's almost as if everything the band and $I$ have done and worked out - together, separately - is right now, right here coalescing into this moment of experienced perfection.

What an oddly pleasurable experience, to be steeped in reflexive thought, yet to feel as though there's no effort involved.

Trey noodles up and down the neck of his guitar, starts playing increasingly intense scales that begin to build the jam's intensity. He's ratcheting it up. My body responds in kind. He works in some sustained, low grunge notes. Fishman follows his cue and starts amping up, too: with drum fills at first, and then hitting a tighter, more intense cymbal ride. All four of them quickly lock into the ascent. The band as a whole crescendos to a fever pitch. l'm dancing and flailing, at the edge of something grandiose. Trey, out of - or through - his distortion-laden super-powerchords, almost imperceptibly re-introduces the song's original coda riff. It's almost too subtle to notice, but he has deftly brought the jam back around full circle. The crowd recognizes what has just happened, where we are, and bursts into a wildly appreciative cheer.

The recognition floors me.

"Amazing," I think. What a feat of determination and magic. I think about all this, eyes still closed, deeply lost in the embodied groove and in the psychic trails of my mind's cognizing. My mind/body/feelings are absolutely entwined, inseparable.

\section{A Commitment to Reflexivity}

A performer's work - as well as a performer's relationship with her or his work - not only reflects the craft and decisionmaking process that eventuate a musical text, it can also evidence explicit reflexion about those choices; about the elements played with, the ideas pursued. Reflexive awareness on the part of a performer can also involve pondering the meaningfulness of performance beyond its formal elements, with "lessons" to be learned about the self and about the self in relation to others.

Reflexivity here signifies two related capacities or functions of performance (Bauman, 1992): formal reflexivity involves thinking about how one is able - what it takes - to communicate, to achieve meaningful and productive interaction; and social-psychological reflexivity, which focuses on the communicative act within a context pervaded by humans interacting and interaffecting each other. Reflexive communication thus signals, as one ethnomusicologist (Béhague, 1992) puts it, an "all-inclusive approach" to communication, encompassing "the various contextual factors affecting performance, the actual musical and extra-musical behavior of participants (performer and audience), and the rules or 
codes of performance defined by the community for a specific context or occasion" (p. 174).

Anastasio (as cited in Gehr and Phish, 1998) describes Phish's performances as something that is the result of a complex process that is inherently reflexive in nature. Anastasio (2005) notes,

I have this feeling that there's a pattern that exists. [....] 'There's tones. It's all there, and it's just the sound of life. And if you listen to it and play it, people respond. 'The way you know that is to watch people while you're playing. You start realizing that they hear it, too. (p. 326)

And, then, in another conversation,

You can't hear what's going on without leaving space in the music. I can't communicate without space. It's more powerful than notes. [ . . . I I like to communicate, so I'm always looking at somebody when I'm onstage. It doesn't matter whether it's another band member or someone dancing in the audience, because if $I^{\prime} \mathrm{m}$ communicating with anybody, if we' re really having a conversation rather than a monologue, everyone hears and feels it. (Anastasio, as cited in Gehr and Phish, 1998, p. 48)

In these statements, Anastasio discusses listening, patterns, responsiveness, interaction, conversation, and spacespecifically, a reflexive space. He seems to understand music as a communicative act that, at its most essential, bridges spaces - and that this bridging is at its best when it fully acknowledges the space(s) it spans. The spaces between the notes thus commingle with the spaces between the human beings enjoying them.

I will briefly elaborate the 1997-1998 era of Phish's performance work right now, as it makes clear their commitment to reflexivity, in both of its inflections. It was at this time that Phish most explicitly realized that their orientations toward their own music-making had an effect on that music. The "shift" that took place in the band's performance modus operandi during this time represented a change in both the content and the form of their live shows. Their live performances took on a more expansive and relaxed feel. Songs such as "Wolfman's Brother," with its lumbering grooves, and "Ghost," with its ethereal-haunt funk, took center stage in Phish's repertoire, often serving up lengthy Type II and Type III Jams. By contrast, perennials such as "Suzy Greenberg," with its Type I jamming, and "Fluffhead," with its complex prog-rock compositional dazzle, receded, becoming only rare treats. New songs came along to refresh the band's repertoire. Not only that, but even the band's orientation toward song selection and song placement - the key elements making up each distinct setlist-had changed from preplanning to a largely on-the-spot approach in which the band would "feel out" what songs they would play in the course of a set, often deciding then and there, as the moment moved them, what to play next. The band would simply go onstage and could end up playing a four-song set that was over an hour long.

Phish's commitment to reflexivity, in other words, was being played out in the music itself, reflecting performance's ongoing, processual nature. At play with this commitment, then, is the idea that the greatest potential of and for performance may lay in its capacity to engender change, in the idea that performance can encourage artistic and expressive dynamism and evolution.

Of course, Phish's commitment to formal reflexivity cannot be understood without also considering its concomitant social-psychological reflexivity. Any change in the formal content of Phish's work necessarily entails a change in their relationships with each other and, just as meaningfully, with their audience. I venture that a good deal of the impetus for Phish's sustained, ongoing reflexive work stems from their connection with, and care for, both each other's and their audience's experiences. Anastasio (as cited in Koransky, 2000) has talked about phans as "a forwardthinking group of people," and has mentioned feeling that "it gives [him] the responsibility to raise the bar musically" (p. 31). Bailey (1993), himself an improviser, resonates this very idea: "Improvisation's responsiveness to its environment puts the performer in a position to be directly influenced by the audience" (p. 44). Every night that Phish take the stage is an exercise in improvising, together, what that night will come to mean. Phish and their audience are thus cosituated in the performance moment.

Reflexivity - the combination of doing and thinking, performing and reflecting - is felt in and through Phish's commitments to flexibility, to groove, to play, and to risk. My elaboration of each of these qua commitments describes, in other words, Phish's actively reflexive orientation towardtheir ongoing work with - performance itself.

My mind/body/feelings are absolutely entwined, inseparable.

Twenty-some minutes into it now, I'm simply delirious. Giddy. Tickled six shades of pink. This is what it's all about. 'This feeling. Right here. Right now. All four band members belt out and repeat the outgoing lyrics of the song we started with back there, back when. "Waiting for the time when I can finally say, 'This has all been wonderful, but now I'm on my way'." They repeat it four more times as they draw the whole thing to a close. I belt it out with them, one hand on my stomach, the other on my heart: "Waiting for the time when I can finally say, "This has all been wonderful, but now I'm on my way'." 


\section{Moving off the Stage (Without Ever Leaving it Behind): An Encore of Concluding Remarks}

Performance is never delimited by the stage's edge or by the performer's being. Indeed, performance matters beyond itself. In my experience of Phish, there is a strong sense of interconnection between the band, the music, the audience, and the overall nature and feel of each show, of each performance event. Phish's performances thus reach out spatiotemporally, mattering - often deeply and intenselyin myriad ways to many people. Phish's performances, as I have come to appreciate them, work simultaneously on at least three levels: on a musical level (performance's strictly formal dimension); on an individual level (performance's intimate psychological and communicative dimension); and on a collective level (performance's metacommunicative, social, and/or cultural dimensions).

In Phish, I see the embodiment of a practice that provides not just a model of performance, but also of the organization of sociopolitical space. The band's commitments as improvising performers can, I believe, be understood as sites for "investigating how the notion of practice might be extended in theories of culture, politics and identity" (litlestad, 2001, p. 29). Psychoaffectively, Phish's performances incite both individual and collective response, eliciting feelings, moving bodies, engaging minds. Epistemically, Phish's performance work involves participation, by band and audience, that yields experiences and understandings of a great many things, from improvisation's do's and don'ts to genre $\mathrm{b}(\mathrm{I})$ ending to formal compositional decisions to both intraand interpersonal communication. Socioculturally, complex relationships are worked out among the band members (as both musicians and humans) and among the band and its audience of devout phans. The values that shape those relationships are first expressed and tested out musically, but they are also meaningful beyond that music, manifested as phan subculture. Some of those musical and extra-musical values, moreover, have political salience and can be resistant and even subversive when experienced within the wider context(s) of mainstream, U.S. culture ${ }^{6}$

Performance, then, should be appreciated as a powerful vehicle for communication, one that always already factors in multiple levels of being human. Emotions, intellects, bodies, sociopolitics, and culture entwine performatively in the spaces defined by - but never limited to - performance, by aesthetic communication. Phish's performance work thus raises questions, whether directly or indirectly, not just about what a musician is and what a musician is supposed to do but also about how humans might act both as creative artists and as persons in the world. Given this, Phish functions for me as a heuristic model, as a useful way of asking after the interrelated epistemological and ontological considerations of musical performance and/as human performance.

\section{Acknowledgments}

The author wishes to thank Dawn Janke for invaluable aid in manuscript preparation.

\section{Declaration of Conflicting Interests}

The author(s) declared no potential conflicts of interest with respect to the authorship and/or publication of this article.

\section{Financial Disclosure/Funding}

The author(s) received no financial support for the research and/or authorship of this article.

\section{Notes}

1. Though not an exact representation, this performative vignette was inspired by a performance of the song "Down with Disease" in Cincinnati, Ohio, on February 21, 2003.

2. The term "phishing," of course, is also used to refer to criminal activity in which, usually through emails, an individual is targeted for finances-related information. Much to the chagrin of phans, this is a more well-known use of the noun and verb forms of "Phish" even though the band's name precedes the emergence of the alternate meaning by at least a decade.

3. A fuller discussion of Phish's music would account for the role of studio recording in the Phish phenomenon. As of this writing, Phish have released 11 studio albums. The band members are very much aware of - and in some ways have struggled with the fact that the studio and the live stage are two very different realms. Though they have made attempts to capture some of the essence of their live shows on tape, they have mostly treated the studio as a place where a different sort of exploration takes place, particularly given the possibilities of multitracking and redoing not available in the live context. Phan discourse evidences mixed feelings about the band's studio work in part, I think, because they sometimes fail to account for the very different criteria (and thus goals) at work in the studio versus the live setting.

4. Phan culture has generated a very useful typology for describing and understanding different kinds of improvisational performance. According to The Phish Companion (Mockingbird, 2004), the term, and the typology that also includes Type II and Type III Jams, was coined by phan John Flynn on fan site The Phish.net (p. 910).

5. Both Brown (2000) and Hamilton (2000) discuss musical improvisation in terms of performative risk and recast "imperfection" as a welcome, constitutive feature of musical improvisational as opposed to something that is to be abjured, or used to fault improvisation and improvisers visà-vis composition and composers. See also Bailey (1993), Berliner (1994), Gould and Keaton (2000), Nettl (1974), and Titlestad (2001). 
6. There is, of course, a great deal of descriptive detail and critical unpacking missing from this essay. Because of space limitations, I have only hinted at the ins and outs of Phish phan culture; at the existence and meaningfulness of the parking lot scene; at the fact that phans, in performing phandom, can become involved in interesting everyday negotiations of identity, values, behaviors that are often in tensive relation to mainstream, U.S. culture.

I would also be remiss if I did not acknowledge, here, a debt to a band, and fan group, that are often considered to be the most obvious forebears to Phish: The Grateful Dead. Indeed, much of what I have shared and argued in this essay could feasibly and productively applied to The Grateful Dead and their fans (Deadheads). This is so precisely because of the centrality of a live, improvisational performance paradigm to both phenomena. So, although Phish's music is substantially different in sound, style, and genre than The Grateful Dead's, it is absolutely the case that there are many similarities between the Phish experience and The Grateful Dead experience. Indeed, members of Phish have acknowledged, all along, that their own orientation toward, and appreciation of, live improvisational performance is quite similar in substance and effect than The Grateful Dead's. It is also the case, of course, that the Deadhead scene has significant overlap with the phan scene. However, as with the music, there are key differences between Deadhead and phan culture. Regrettably, I do not have the space to elaborate and unpack these differences and similarities, both musical and cultural. Finally, though I have not directly cited Dead-related scholarship, I have had the pleasure of engaging it, and am grateful for the ways in which it has informed my ability to think through and feel into my experiences with/of Phish (see, c.g., Adams, 1998; Millman \& Beeder, 1994; Pattacini, 2000; Pearson, 1987; Rodriguez, Gintautas, \& Pepe, 2009).

\section{References}

Adams, R. (1998). Inciting sociological thought by studying the Deadhead community: Engaging publics in dialogue. Social Forces, 77(1), 1-25.

Alperson, P. (1984). On musical improvisation. Journal of Aesthetics and Art Criticism, 43(1), 17-29.

Anastasio, T. (2005). "It's about doing what you're told to do" (interview). In A. DeCurtis (Ed.), Artists talk about life and work (pp. 315-327). Milwaukee, WI: Hal Leonard.

Auslander, P. (2006b). Performing glam rock: Gender and theatricality in popular music. Ann Arbor: University of Michigan Press.

Bakhtin, M. (1984a). Problems of Dostoevsky s poetics. (C. Emerson, Ed. \& Trans.). Minneapolis: University of Minnesota Press.

Bakhtin, M. (1984b). Rabelais and his world. (H. Iswolsky, Trans.). Bloomington: Indiana University Press.

Bailey, D. (1993). Improvisation: Its nature and practice in music. New York: Da Capo.
Bauman, R. (1992). Performance. In R. Bauman (Ed.), Folklore, cultural performances, and popular entertainment: $A$ communication-centered handbook (pp. 41-49). New York: Oxford University Press.

Béhague, G. H. (1992). Music performance. In R. Bauman (Ed.), Folklore, cultural performances, and popular entertainment: A communication-centered handbook (pp. 172-178). New York: Oxford University Press.

Berliner, P. F. (1994). Thinking in jazz: The infinite art of improvisation. Chicago: University of Chicago Press.

Brown, L. B. (2000). "Feeling my way": Jazz improvisation and its vicissitudes A plea for imperfection. Journal of Aesthetics and Art Criticism, 58, 112-123.

Butler, J. (1990). Gender trouble: Feminism and the subversion of identity. New York: Routledge.

Chvasta, M. (2002, November 22). Conceptualizing risk in performance. Paper presented at the National Communication Association Convention, Sheraton New Orleans Hotel, New Orleans.

DeChaine, D. R. (2002). Affect and embodied understanding in musical experience. Text and Performance Quarterly, 22(2), 79-98.

Denzin, N. K. (2003). Performance ethnography: Critical pedagogy and the politics of culture. Thousand Oaks, CA: SAGE.

Dolan, J. (2005). Utopia in performance: Finding hope at the theater. Ann Arbor: University of Michigan Press.

Ellis, A. (2000, August). Flippertronics: Phish's Trey Anastasio trips out on guitar loops. Guitar Player, 90-102.

Gehr, R., \& Phish. (1998). The Phish book. New York: Random.

Gill, C. (1994, September). Trey Anastasio's Phish tales. Guitar Player, 39-42.

Goodall, H. L. (1991). Living in the rock $n$ roll mystery: Reading context, self, and others as clues. Carbondale: Southern Illinois University Press.

Gould, C. S., \& Keaton, K. (2000). The essential role of improvisation in musical performance. Journal of Aesthetics and Art Criticism, 58, 143-148.

Hamilton, A. (2000). The art of improvisation and the aesthetics of imperfection. British Journal of Aesthetics, 40, 168-185.

Jones, S. H. (2007). Torch singing: Performing resistance and desire from Billie Holiday to Edith Piaf. Lanham, MD: Altamira Press.

Koransky, J. (2000, June). Phundamental improvisation: Phish's tale of musical innovation from the stage to the farmhouse. Down Beat, 24-31.

LivePhish.com. (2003). Live Phish downloads. Retrieved November 1,2006 from http://www.livephish.com/packages/ phish_it.asp

Lyotard, J.-F. (1984). The postmodern condition: A report on knowledge (G. Bennington \& B. Massumi, Trans.). Minneapolis: University of Minnesota Press.

Marcuse, H. (1955). Eros and civilization: A philosophical inquiry into Freud. Boston: Beacon. 
Millman, R. B., \& Beeder, A. B. (1994). New psychedelic culture: LSD, ecstasy, "rave" parties and the Grateful Dead. Psychiatric Annals, 24, 148-150.

Miracle, A. W. (1992). Play. In R. Bauman (Ed.), Folklore, cultural performances, and popular entertainment: A communicationcentered handbook (pp. 60-66). New York: Oxford University Press.

Mockingbird Foundation, The. (Ed.) (2004). The Phish Companion: A guide to the band and their music (2nd ed.). San Francisco: Backbeat.

Nettl, B. (1974). Thoughts on improvisation: A comparative approach. Musical Quarterly, 40(1), 1-19.

Pattacini, M. M. (2000). Deadheads yesterday and today: An audience study. Popular Music \& Society, 24(1), 1-14.

Pearson, A. (1987). The Grateful Dead phenomenon: An ethnomethodological approach. Youth \& Society, 18, 418-432.

Resnicoff, M. (1996, May). Swimming against the tide: Phish's Trey Anastasio braves new waters. Guitar Player, 73-80.

Rodriguez, M. A., Gintautas, V., \& Pepe, A. (2009). A Grateful Dead analysis: The relationship between concert and listening behavior analysis. First Monday, 14(1). Retrieved from http:// www.uic.edu/htbin/cgiwrap/bin/ojs/index.php/fm/article/ view $/ 2273$

Schechner, R. (1998). Performance theory. New York: Routledge. Thompson, D. (1997). Go Phish. New York: St. Martin's.

Titlestad, M. (2001). Contesting maps: Musical improvisation and narrative. Pretexts: Literary and Cultural Studies, 10(1), 21-36.

Turner, V. (1988). The anthropology of performance. New York: PAJ.

Wharton, M. (Producer/Director). (2004). Phish: It (Motion picture). United States: WSM.

Zbikowski, L. M. (2004). Modeling the groove: Conceptual structure and popular music. Journal of the Royal Musical Association, 129, 272-297.

\section{Bio}

Jnan A. Blau is assistant professor of communication studies at California Polytechnic State University where he teaches courses in performance studies and intercultural communication. His research works out of - and back into the nexus of performance studies and popular music studies. 